\title{
Vulnerabilidades ocupacionais e percepção de saúde em trabalhadores do SUS
}

\author{
Ada Ávila Assunção* \\ Ana Flávia Machado** \\ Tânia Maria de Araújo***
}

\begin{abstract}
Este artigo desenvolve uma tipologia de precariedade nos vínculos de trabalho, considerando outras dimensões além daquelas tradicionais, como tipo de vínculo, jornada e rendimento de trabalho. Outros aspectos do local de trabalho e da alocação de tempo em atividades e tarefas fora do ambiente laboral afetam a inserção dos indivíduos no mercado de trabalho. Assim, a partir da flexibilidade do método e da relativamente grande disponibilidade de informações sobre o indivíduo e seu desempenho socioeconômico, a presente investigação recorreu à aplicação do Método Grade of Membership (GoM) aos dados de 1.808 trabalhadores da rede municipal de saúde de Belo Horizonte que participaram de um inquérito epidemiológico em 2009. Foram considerados elegíveis todos os profissionais vinculados ao serviço público municipal de saúde, independente do vínculo empregatício (permanente, temporário, estágio). O estudo foi aprovado pelo Comitê de Ética em Pesquisa da Universidade Federal de Minas Gerais (parecer $n^{\circ}$ 542/07). Os resultados apresentados convergem para as reflexões acerca da crescente constatação da vulnerabilidade dos trabalhadores de saúde em função das condições de trabalho precárias, além de indicaram a relevância da abordagem da atividade de trabalho, no sentido de identificar agentes estressores e outros fatores do ambiente relacionados às situações nocivas e de adoecimento. Algumas características dos indivíduos (idade, sexo, tempo de serviço, etc.) que conformam a população-alvo não são passíveis de ações externas, no entanto, as políticas podem modificar os fatores localizados em torno do núcleo individual.
\end{abstract}

Palavras-chave: Mercado de trabalho. Saúde. Vulnerabilidade. Trabalhadores do SUS. Tipologia GoM.

\footnotetext{
* Médica; mestre e doutora em Ergonomia pela École Pratique Des Hautes Études e pós-doutora em Saúde Pública pela Fundação Osvaldo Cruz. Professora associada do Departamento de Medicina Preventiva e Social da Universidade Federal de Minas Gerais.

** Economista; mestre em Economia pela Universidade Federal de Minas Gerais, doutora em Economia pela Universidade Federal do Rio de Janeiro e pós-doutora em Economia pelo International Poverty Centre - PNUD/DF. Professora associada do Departamento de Ciências Econômicas da Universidade Federal de Minas Gerais.

*** Psicóloga; mestre em Saúde Comunitária e doutora em Saúde Pública pela Universidade Federal da Bahia e pósdoutora em Estresse Ocupacional pela University of Massachusetts. Professora titular do Departamento de Saúde da Universidade Estadual de Feira de Santana.
} 


\section{Introdução}

Sabe-se que os indivíduos morrem mais jovens ou têm pior saúde de acordo com suas condições de vida e de trabalho, ou dependendo do patrimônio cultural e material de suas famílias. As aclarações sobre as persistentes diferenças na distribuição populacional da morbidade e mortalidade, confirmadas para doenças crônicas e causas de morte, explicam o foco nas dimensões sociais das desigualdades em saúde, as quais comumente seguem um gradiente de desvantagem para os grupos mais vulneráveis socialmente (MARMOT, 2005).

A magnitude das desigualdades em saúde pode variar entre os diferentes grupos ocupacionais, devido às diferenças de condições de emprego e de trabalho (LAHELMA et al., 2009; BENAVIDES et al., 2000). Estatuto do emprego e qualidade do trabalho exercem fortes efeitos sobre a saúde dos adultos. Está bem fundamentado que tais efeitos não se referem estritamente à dimensão material, incluindo também os fatores psicossociais dos ambientes (SIEGRIST; MARMOT, 2004).

Inserção vulnerável no mercado de trabalho compreende as situações de fraca ou nenhuma proteção social, baixo nível de renda, baixa escolaridade, emprego temporário ou ausência de vínculo, jornadas extensas, exposição às elevadas cargas físicas e psicossociais das tarefas, trabalho envolvendo periculosidade e o trabalho sem sentido.

Os trabalhadores da saúde (TS) estão duplamente envolvidos na problemática das desigualdades em saúde: como cidadãos, estão mais ou menos vulneráveis, dependendo de sua inserção ocupacional e situação socioeconômica (SMITH, et al., 2007); e, como trabalhadores, as condições que eles encontram para trabalhar coincidem com a qualidade dos serviços prestados às populações (OMS, 2008; D'AVILA et al., 2010; TARNOW-MORDI et al., 2000).

Estudos recentes indicam aumento da proporção de TS insatisfeitos que abandonaram seus postos ou continuaram trabalhando apesar da insatisfação com a diminuição da autonomia, o aumento da pressão tanto da hierarquia quanto dos pacientes, o excesso de tarefas burocráticas, o fraco reconhecimento social, as condições inadequadas de trabalho e os baixos salários (KAUR et al., 2009; WADA et al., 2009; WALLACE et al., 2009).

Mundialmente, as reformas sanitárias em curso objetivam ampliar o acesso aos serviços e controlar os custos da assistência. Disponibilidade e qualidade dos recursos humanos são consideradas fatores-chave para o desempenho das organizações e sistemas de saúde (MARCHAL; KEGELS, 2003). Entretanto, as medidas para controlar os custos da assistência, com frequência, entram em conflito com os requisitos necessários para proporcionar um nível adequado de cuidado a ser prestado (MAWN et al., 2010). Paralelamente, no Brasil, as reformas sanitárias se apoiaram fortemente no trabalho precário (BUCHAN et al., 2011).

A saúde dos profissionais do SUS, anteriormente amparada por legislação genérica de saúde do trabalhador, é objeto de uma Portaria do Ministério da Saúde (BRASIL, 2011), publicada em 2011, que estabelece as diretrizes da Política Nacional de Promoção da Saúde do Trabalhador do Sistema Único de Saúde (SUS). Trata-se de um reconhecimento das especificidades do trabalho no SUS e da necessidade de adequações dos ambientes sanitários, visando a proteção dos profissionais implicados na assistência aos usuários. As exigências dos cidadãos e o próprio SUS, ao buscarem aumento da eficiência e da equidade, requisitam um trabalhador capaz de dominar uma gama de conhecimentos e habilidades, bem como ter uma visão geral do contexto e um forte compromisso social.

Os princípios e diretrizes a serem observados na elaboração dos planos, programas, projetos e ações de saúde voltados à população trabalhadora do SUS incluem, entre outros, a valorização dos trabalhadores, o que pressupõe reconhecer o papel fundamental do trabalhador na atenção integral à saúde da população, garantindo políticas e ações que permitam o crescimento pessoal e profissional 
do trabalhador e estimulem relações e condições de trabalho adequadas.

No Brasil, de acordo com dados do CNES de 2008 e 2009, havia aproximadamente 2 milhões de profissionais, incluindo médicos, odontólogos, farmacêuticos, enfermeiros, técnicos e auxiliares de enfermagem. A partir de dados da Rais de 2008, foram estimados 2,5 milhões de empregos formais privados e da administração pública, vinculados à saúde humana, núcleo do setor saúde (BRASIL, 2009).

Considerando-se o macrossetor saúde, em que se incluem atividades de assistência social, psicossocial, regulação, ensino, pesquisa, atividades de saneamento, entre outros, são 4 milhões de vínculos, atingindo $10 \%$ do total da economia (BRASIL, 2009).

Em Belo Horizonte, houve aumento do quadro de trabalhadores não efetivos, cujos direitos contratuais e proteção trabalhista não foram contemplados para uma parcela deles (COELHO et al., 2009). Dados do Ministério da Saúde assumem que aproximadamente 800 mil trabalhadores da saúde estavam em situação de emprego precário em 2006, equivalendo a quase $40 \%$ da força de trabalho do setor (BRASIL, 2006).

Em suma, o Sistema Único de Saúde (SUS) não escapou da realidade da precarização do trabalho no país (CONASEMS, 2007). No entanto, medidas vêm sendo tomadas com o objetivo de reverter o quadro. Políticas específicas visam promover relações estáveis de trabalho, garantia dos direitos do trabalhador e erradicação progressiva dos vínculos precários do trabalho existentes no setor (MACHADO; KOSTER, 2011). Quanto a Belo Horizonte, várias medidas têm sido adotadas no sentido de minimizar o quadro de precarização do trabalho e do emprego no SUS-BH, tais como realização de concursos públicos para provimento de cargos da saúde de 2002 a 2006 e estabelecimento de um Plano de Cargos e Carreiras da Saúde (PREFEITURA MUNICIPAL DE BELO HORIZONTE, 2007).

A Secretaria Municipal de Saúde (SMSA) de Belo Horizonte implantou, em 2002, a Estratégia Saúde da Família (ESF), com o objetivo de impulsionar a reorientação do modelo assistencial, com ênfase na Atenção Primária à Saúde (APS). Avaliações sobre o desempenho do modelo assistencial implantado demonstram que o município tem avançado nos atributos essenciais da APS. Apesar dos avanços, ainda existem desafios a serem superados, particularmente no que se refere à gestão do trabalho (SECRETARIA MUNICIPAL DE SAÚDE DE BELO HORIZONTE, 2008; LOPES; MATOS, 2010).

A abordagem das articulações entre as características dos indivíduos e das ocupações é impregnada de contingências e de relações não lineares; por isso, os estudos que focalizam as associações entre emprego e situação de saúde enfrentam limites quanto ao dimensionamento insuficiente das condições de trabalho, entre outros. Impasses e dilemas metodológicos permeiam os projetos investigativos, indicando os limites das abordagens unifatoriais. Medidas multidimensionais e que possam resumir informações em um número determinado de grupos são necessárias para identificar as vulnerabilidades em que se encontram os TS.

A elaboração de uma tipologia de precariedade nos vínculos de trabalho busca contribuir para a construção de indicadores que considerem outras dimensões, além daquelas tradicionais como tipo de vínculo, jornada e rendimento de trabalho. Outros aspectos do local de trabalho, assim como de alocação de tempo em atividades e tarefas fora do ambiente laboral, afetam a inserção dos indivíduos no mercado de trabalho. Considerando, portanto, a flexibilidade do método e a relativamente grande disponibilidade de informações acerca do indivíduo e de seu desempenho socioeconômico, a presente investigação recorreu ao método Grade of Membership (GoM), que possibilita operacionalizar o conceito de vulnerabilidade social, ao analisar a presença de múltiplas condições de trabalho e emprego em uma população com grande variabilidade e diversidade quanto aos aspectos de interesse. Além disso, por meio de tal abordagem, é possível identificar os perfis e contribuir para a formulação de ações e políticas específicas que atendam à peculiaridade dos grupos. 


\section{Metodologia}

\section{Banco de dados}

O presente estudo incluiu 1.808 trabalhadores da rede municipal de saúde de Belo Horizonte que participaram de um inquérito epidemiológico em 2009. Foram considerados elegíveis todos os profissionais vinculados ao serviço público municipal de saúde, independente do vínculo empregatício (permanente, temporário, estágio), em efetivo exercício profissional na unidade sorteada. Os questionários não identificavam os respondentes, preservando a confidencialidade dos dados obtidos. $O$ estudo foi aprovado pelo Comitê de Ética em Pesquisa da Universidade Federal de Minas Gerais (parecer no 542/07). Termo de consentimento livre e esclarecido foi requerido de todos os participantes do estudo.

A amostra foi composta por indivíduos sorteados por procedimento aleatório e estratificada segundo distrito sanitário, nível de complexidade da assistência (centros de saúde, especialidades, urgência e gerências distritais) e ocupação. Foram substituídos, respeitando-se a função ou cargo, nível de assistência e área geográfica, aqueles que não se encontravam no serviço por motivo de férias, transferência, aposentadoria ou morte.

Para o cálculo da amostra, considerou-se o universo de 13.602 trabalhadores da saúde na época da coleta de dados. Foi estimada uma amostra de 1.495 trabalhadores, com base na prevalência de 34,2\% de exposição a riscos biológicos (evento de interesse de maior prevalência no segmento estudado), nível de confiança de $95 \%$ e erro de delineamento de $3 \%$, sendo ampliada para 1.794 pessoas, considerando uma possível perda de $20 \%$.

O preenchimento do questionário foi conduzido por um entrevistador treinado, que se dirigiu à unidade do participante após contato e confirmação da presença do entrevistado. Foram realizadas até três tentativas no intuito de localizar o trabalhador sorteado. Considerou-se perda quando o trabalhador não foi encontrado na terceira tentativa.
A composição final da amostra indica que as mulheres representaram a maioria da população estudada $(71,6 \%) ; 31,8 \%$ tinham até 34 anos, sendo que, no total, a variação foi de 16 a 73 anos; a média de idade foi $40,8 \pm 11,1$ anos; $54,4 \%$ declararam viver com um companheiro; $54,2 \%$ tinham ensino médio, técnico ou superior incompleto; e $53,6 \%$ dos TS estudados estavam no serviço público há menos de dez anos. A jornada semanal de trabalho na unidade era de 40 a 44 horas para $53,4 \%$ dos respondentes e cerca de $38,0 \%$ relataram ter outro emprego.

\section{Variáveis selecionadas}

Diferentes dimensões do trabalho e da saúde dos trabalhadores foram avaliadas: características sociodemográficas; hábitos de vida; situações de saúde; características do emprego; aspectos psicossociais do trabalho; e trabalho doméstico.

Os transtornos mentais comuns (TMC) foram avaliados de acordo com escores obtidos no Self Reporting Questionnaire (SRQ20), que é um instrumento desenvolvido pela Organização Mundial da Saúde (OMS) para avaliar morbidade psíquica em países em desenvolvimento, cujo resultado identifica nível de suspeição de TMC (SANTOS et al., 2009). É composto por 20 questões, com respostas dicotômicas (sim ou não), incluindo sintomas emocionais e físicos associados a quadros psiquiátricos. Definiu-se o ponto de corte para classificação de suspeitos de TMC em sete ou mais respostas positivas, procedimento adotado em outros estudos (ARAÚJO et al., 2003a e 2005).

Já os aspectos psicossociais do trabaIho foram avaliados pelo Job Content Questionnaire (JCQ). Trata-se de um instrumento baseado no Modelo Demanda-Controle (KARASEK; THEÖRELL, 1990; ARAÚJO; KARASEK, 2008; ARAÚJO, 2003b), que privilegia duas dimensões psicossociais: o controle sobre o trabalho e a demanda psicológica advinda do trabalho. A partir da combinação dessas duas dimensões, o modelo distingue situações de trabalho específicas que, por sua vez, estruturam riscos diferenciados à saúde (ARAÚJO, 2003b). 
O Manual do JCQ (www.JCQCenter. org) foi utilizado para a construção dos escores de demanda psicológica (incluindo questões relacionadas ao ritmo de trabalho, tempo para a realização das tarefas, tarefas conflitantes, volume excessivo de trabalho) e de controle sobre o próprio trabalho, incluindo duas subescalas: uso de habilidades (avaliando aprendizagem de coisas novas, criatividade, desenvolvimento de habilidades especiais, possibilidade de realização de diferentes tarefas); e autoridade decisória (liberdade para decidir como realizar as tarefas, possibilidade de tomada de decisões) (ARAÚJO, 2003b).

Para a análise, os escores de demanda psicológica e de controle foram dicotomizados com base na mediana da distribuição de cada uma dessas variáveis: os valores iguais ou abaixo da mediana foram categorizados como baixa demanda ou baixo controle; e os acima, como alta demanda ou alto controle.

A partir da combinação entre níveis de demanda e controle, foram constituídos os quatro grupos previstos no Modelo Demanda-Controle: baixa exigência (combinação de baixa demanda e alto controle); trabalho passivo (baixa demanda e baixo controle); trabalho ativo (alta demanda e alto controle); e alta exigência (alta demanda e baixo controle) (KARASEK; THEÖRELL, 1990; SOUZA et al. 2010).

Para a mensuração da variável sobrecarga doméstica, considerou-se a realização de quatro tarefas domésticas básicas - cozinhar, limpar, lavar e passar -, conforme indicador proposto por Thierney et al. (1990), ponderada pelo número de potenciais beneficiários do trabalho doméstico (número de pessoas no domicílio). A sobrecarga doméstica foi, portanto, avaliada a partir do somatório das tarefas domésticas, ponderado pelo número de moradores, exceto a própria entrevistada ( $\Sigma$ lavar+ passar + limpar + cozinhar) $\times(\mathrm{M}-1)$ (ARAÚJO et al., 2005). Para fins de análise, o escore de sobrecarga doméstica foi dicotomizado com base nos tercis da distribuição obtida: baixa sobrecarga (correspondeu aos valores iguais ou abaixo do segundo tercil); e alta sobrecarga (valores acima do segundo tercil).
Compatibilidade entre escolaridade e cargo foi outra variável escolhida. Foram considerados compatíveis os empregos nos quais os trabalhadores se encontravam em cargos adequados ao seu nível de escolaridade. Subqualificados foram aqueles que ocupavam cargos que exigiam maior nível de escolaridade do que o reportado pelo entrevistado-trabalhador, enquanto sobrequalificados foram aqueles que tinham escolaridade superior à exigida pelo cargo. A construção dessa variável foi facilitada pelo fato de os cargos estarem descritos conforme habilidades educacionais requeridas pelo posto de trabalho.

Para a construção de tipologias de perfis utilizando-se o método GoM, foram analisadas as seguintes variáveis: informações sociodemográficas (sexo, idade, cor); hábitos de vida (participação em atividades de lazer, sociais e culturais, prática e frequência de atividades físicas); condições de saúde (relato de depressão e ansiedade, presença de transtorno mental comum -TMC, distúrbios de sono, estado vacinal contra hepatite $B$ ); características do emprego (treinamento, tipo de vínculo, jornada de trabalho, outros empregos, relação escolaridade e nível da ocupação, renda); aspectos psicossociais do trabalho e demandas e controle sobre as tarefas; e trabalho doméstico (atividades realizadas e sobrecarga doméstica).

\section{Método GoM}

O método Grade of Membership (GoM) - Grau de Pertencimento - pertence à teoria de conjuntos nebulosos (fuzzy sets), a qual não pressupõe a dicotomia fundamental de a teoria clássica pertencer ou não a apenas um conjunto. Em conjuntos nebulosos, opera-se com a possibilidade de um elemento pertencer a mais de um conjunto. O método identifica, entre os indivíduos da base de dados, dois ou mais perfis de referência (ou perfis extremos), de acordo com suas características próprias descritas pelas variáveis. Identifica também os graus de pertencimento dos indivíduos a cada perfil extremo, sendo de $100 \%$, se o indivíduo tiver todas as características 
do perfil, de $0 \%$, caso contrário, e entre $100 \%$ e $0 \%$, quando o indivíduo possuir características de mais de um perfil extremo.

Com base em cinco hipóteses, o modelo de probabilidade para a construção do procedimento de estimação de máxima verossimilhança é formulado. O modelo de probabilidade, para uma amostra aleatória, é o produto do modelo multinomial com a probabilidade de cada indivíduo segundo determinada variável.

Do banco de dados gerado foram selecionadas, para o presente estudo, 29 variáveis consideradas pertinentes para descrever o quão vulnerável era a condição socio-ocupacional. Como o GoM exige variáveis discretas, elas foram definidas conforme disposto na Tabela 1.

O número de perfis extremos (ou perfis de referência) definido pelo pesquisador resulta na dimensão final da tipologia, ou seja, em categorias puras e mistas. Os tipos mistos combinam características de dois ou mais tipos puros, os quais, por sua vez, correspondem, basicamente, aos perfis extremos. Nesse trabalho, foram

TABELA 1

Distribuição dos trabalhadores de saúde entrevistados, segundo variáveis utilizadas pelo método Belo Horizonte - 2009

\begin{tabular}{|c|c|c|c|c|c|}
\hline Variáveis & Categorias & $\%$ & Variáveis & Categorias & $\%$ \\
\hline \multirow{4}{*}{ Sexo } & Homens & 28,0 & \multirow{4}{*}{$\begin{array}{l}\text { Outros } \\
\text { trabalhos }\end{array}$} & Estado & 6,1 \\
\hline & Mulheres & 70,9 & & Nível federal & 1,2 \\
\hline & \multirow[t]{2}{*}{ Missing } & \multirow[t]{2}{*}{1,1} & & Iniciativa privada carteira assinada & 4,3 \\
\hline & & & & Iniciativa privada sem carteira privada & 4,0 \\
\hline \multirow[t]{7}{*}{ Idade } & 14 a 19 anos & 2,7 & & Tem outro trabalho por conta própria & 8,3 \\
\hline & 20 a 39 anos & 16,2 & & Não tem outro trabalho & 54,5 \\
\hline & 30 a 39 anos & 24,1 & & Missing & 12,8 \\
\hline & 40 a 49 anos & 32,2 & & & \\
\hline & 50 a 80 anos & 23,5 & Jornada & Menos de 20 horas & 4,9 \\
\hline & \multirow[t]{2}{*}{ Missing } & \multirow[t]{2}{*}{1,3} & no outro & 21 a 30 horas & 10,2 \\
\hline & & & trabalho & 31 a 40 horas & 39,3 \\
\hline \multirow[t]{3}{*}{ Cor } & Branca & 42,4 & & 41 a 44 horas & 4,4 \\
\hline & Não branca & 52,8 & & Mais de 44 horas & 26,9 \\
\hline & Missing & 4,9 & & Missing & 14,3 \\
\hline \multirow[t]{3}{*}{ Treinamento } & Não & 48,5 & \multirow{3}{*}{$\begin{array}{l}\text { Cuida de } \\
\text { criança }\end{array}$} & Não & 40,6 \\
\hline & Sim & 47,8 & & Sim & 35,9 \\
\hline & Missing & 3,7 & & Missing & 23,5 \\
\hline \multirow{3}{*}{$\begin{array}{l}\text { Vínculo } \\
\text { empregatício }\end{array}$} & Não estável & 40,0 & \multirow{3}{*}{$\begin{array}{l}\text { Faz compras no } \\
\text { supermercado }\end{array}$} & Não & 14,5 \\
\hline & Estável & 57,2 & & Sim & 81,3 \\
\hline & Missing & 2,8 & & Missing & 4,1 \\
\hline \multirow{11}{*}{$\begin{array}{l}\text { Jornada } \\
\text { semanal } \\
\text { de trabalho } \\
\text { (horas) }\end{array}$} & 8 & 6,3 & \multirow{4}{*}{$\begin{array}{l}\text { Leva criança } \\
\text { para escola }\end{array}$} & Não & 52,3 \\
\hline & 10 & 0,2 & & Sim & 21,1 \\
\hline & 12 & 0,8 & & Missing & 26,6 \\
\hline & 20 & 14,3 & & & \\
\hline & 24 & 3,4 & Faz pequenos & Não & 34,9 \\
\hline & 30 & 17,1 & consertos em & Sim & 53,7 \\
\hline & 36 & 3,4 & casa & Missing & 11,4 \\
\hline & 40 & 48,6 & & & \\
\hline & 44 & 3,4 & Cuida de idosos, & Não & 59,0 \\
\hline & \multirow[t]{2}{*}{ Missing } & \multirow[t]{2}{*}{2,5} & crianças e & Sim & 16,6 \\
\hline & & & doentes & Missing & 24,4 \\
\hline Outros & Prefeitura de $\mathrm{BH}$ & 3,2 & & & \\
\hline trabalhos & Outra prefeitura & 5,6 & & & \\
\hline
\end{tabular}




\begin{tabular}{|c|c|c|c|c|c|}
\hline Variáveis & Categorias & $\%$ & Variáveis & Categorias & $\%$ \\
\hline \multirow{3}{*}{$\begin{array}{l}\text { Responsável } \\
\text { pelo } \\
\text { domicílio }\end{array}$} & Não & 48,8 & \multirow{3}{*}{$\begin{array}{l}\text { Distúrbios de } \\
\text { sono }\end{array}$} & Não & 74,8 \\
\hline & Sim & 45,1 & & Sim & 14,2 \\
\hline & Missing & 6,1 & & Missing & 11,1 \\
\hline \multirow{7}{*}{$\begin{array}{l}\text { Dias } \\
\text { dedicados } \\
\text { a trabalho } \\
\text { no domicílio }\end{array}$} & Todos os dias da semana & 39,0 & \multirow[t]{4}{*}{ Falta ao trabalho } & Não & 55,5 \\
\hline & 3 ou mais dias da semana & 14,6 & & Sim & 42,7 \\
\hline & 1 ou 2 dias da semana & 11,8 & & Missing & 1,8 \\
\hline & Apenas no final de semana & 2,1 & & & \\
\hline & Não realizou atividade doméstica & 6,5 & \multirow{6}{*}{$\begin{array}{l}\text { Faixa de } \\
\text { rendimento do } \\
\text { trabalho }\end{array}$} & Entre meio e 1 salário mínimo & 15,4 \\
\hline & \multirow[t]{2}{*}{ Missing } & \multirow[t]{2}{*}{7,1} & & Entre 1 e 2 salários mínimos & 33,1 \\
\hline & & & & Entre 2 e 5 salários mínimos & 0,0 \\
\hline Realiza & Não & 25,4 & & Entre 5 e 10 salários mínimos & 28,7 \\
\hline atividades & Sim & 73,0 & & Mais de 10 salários mínimos & 14,3 \\
\hline de lazer & Missing & 1,5 & & Missing & 8,5 \\
\hline \multirow{3}{*}{$\begin{array}{l}\text { Realiza } \\
\text { atividades } \\
\text { culturais }\end{array}$} & Não & 42,7 & \multirow[t]{3}{*}{$\mathrm{SRQ}$} & TMC negativo & 70,0 \\
\hline & Sim & 30,9 & & TMC positivo & 22,0 \\
\hline & missing & 26,4 & & Missing & 8,0 \\
\hline \multirow{4}{*}{$\begin{array}{l}\text { Realiza } \\
\text { atividades } \\
\text { sociais }\end{array}$} & Não & 22,3 & \multirow[t]{6}{*}{ JCQ } & Alta exigência & 16,3 \\
\hline & Sim & 51,3 & & Trabalho ativo & 6,6 \\
\hline & Missing & 26,3 & & Baixa exigência & 10,8 \\
\hline & & & & Trabalho passivo & 55,1 \\
\hline \multirow{4}{*}{$\begin{array}{l}\text { Realiza } \\
\text { atividades } \\
\text { físicas }\end{array}$} & Não & 23,4 & & \multirow[t]{2}{*}{ Missing } & \multirow[t]{2}{*}{11,2} \\
\hline & Sim & 50,1 & & & \\
\hline & \multirow[t]{2}{*}{ Missing } & \multirow[t]{2}{*}{26,5} & \multirow{4}{*}{$\begin{array}{l}\text { Tomou vacina } \\
\text { contra hepatite } \\
\text { B? }\end{array}$} & Não & 5,3 \\
\hline & & & & Sim & 84,3 \\
\hline \multirow{5}{*}{$\begin{array}{l}\text { Frequência } \\
\text { de } \\
\text { atividades } \\
\text { físicas }\end{array}$} & 3 ou mais vezes por semana & 23,6 & & Missing & 10,4 \\
\hline & 1 ou 2 vezes por semana & 33,2 & & & \\
\hline & Nunca & 29,4 & \multirow{5}{*}{$\begin{array}{l}\text { Ocupação } \\
\text { compatível com } \\
\text { escolaridade }\end{array}$} & Compatível & 73,7 \\
\hline & Missing & 13,8 & & Sobrequalificados & 13,4 \\
\hline & & & & Subqualificados & 8,2 \\
\hline \multirow{5}{*}{$\begin{array}{l}\text { Incidência de } \\
\text { depressão e } \\
\text { insônia }\end{array}$} & Não & 77,5 & & \multirow[t]{2}{*}{ Missing } & \multirow[t]{2}{*}{4,6} \\
\hline & Sim & 11,3 & & & \\
\hline & Missing & 11,2 & Sobrecarga de & Baixa sobrecarga & 42,0 \\
\hline & & & trabalho no & Alta sobrecarga & 31,6 \\
\hline & & & domicílio & Missing & 26,4 \\
\hline
\end{tabular}

Fonte: Elaboração dos autores a partir dos inquéritos da Pesquisa Condições de Trabalho, Condições de Emprego e Saúde dos Trabalhadores da Saúde, financiada pela Fapemig.

definidos três que, por combinatória, geram dez perfis.

Para cada elemento (neste caso, indivíduo) em um conjunto nebuloso existe um grau de pertinência (gik), que representa o grau com que o elemento i pertence ao conjunto/perfil $\mathrm{k}$, assumindo valores entre 0 (zero) e 1 (um), inclusive. Se gik assume valores superiores a zero e inferiores a um, o indivíduo tem pertencimento (parcial) a mais de um perfil de referência (MANTON et al., 1994).

Os perfis extremos resultam da estimação por máxima verossimilhança, ao passo que as categorias finais da tipologia, puras e mistas, são definidas conforme a intensidade do grau de pertencimento ou pela localização em relação a um dos perfis extremos. Estes perfis são caracterizados pela análise entre a razão de probabilidades a cada resposta da 
variável empregada (lambda) e a frequência marginal das respostas. De acordo com Melo (2006), considera-se que determinada resposta à variável discrimina o perfil quando a razão entre o lambda e a frequência marginal de cada resposta for superior a 1,2.

\section{Resultados}

\section{Perfis extremos}

A Tabela 2 traz a descrição das características prováveis dos perfis extremos, destacando aquelas que discriminam, uma vez que os valores da razão das probabilidades são superiores a 1,2 (realçados na tabela).

Da leitura dos resultados, apreende-se que o perfil 1 discrimina para homens; em faixas etárias mais jovens; brancos; jornadas de trabalho semanais entre 12 e 24 horas ou entre 36 e 40 horas; para aqueles com duplo emprego, em qualquer uma das possibilidades, com exceção da própria Prefeitura de Belo Horizonte e do governo do Estado; jornada no outro trabalho inferior a 20 horas ou acima de 41 horas semanais; sem atividades no domicílio e sem ser por ele responsável; prática de atividades de lazer; faixas de rendimento inferior a um salário mínimo ou superior a dez salários mínimos; trabalho ativo ou de baixa exigência; compatibilidade entre escolaridade e cargo; baixa sobrecarga doméstica. De acordo com essa descrição, pode-se concluir que, no perfil 1, predominam trabalhadores menos vulneráveis quanto às características individuais e à carga doméstica, o que é coerente com a condição de não estar doente, trabalhando em condições favoráveis.

Já o perfil 2 discrimina para mulheres; idade entre 40 e 49 anos; não brancos; jornadas de trabalho semanais de $30 \mathrm{e}$ 44 horas; para aqueles que não têm outro trabalho; jornada no outro trabalho de 21 a 30 horas semanais; cuida de crianças no domicílio, mas não as leva à escola; cuida de idosos e doentes; responsável pelo domicílio; envolvidos em atividades domésticas todos os dias; pratica atividade de lazer; não faz atividade física regularmente; apresenta distúrbios do sono; falta ao trabalho; faixas de rendimento entre 1 e 2 salários mínimos ou entre 5 e 10 salários mínimos; relato compatível com TMC; alta exigência ou trabalho passivo; sobrecarga doméstica. No perfil extremo 2, portanto, estão concentrados trabalhadores mais vulneráveis quanto às características individuais e à carga doméstica e pobre vida extratrabalho, coerente com a condição de estar doente, trabalhando em condições desfavoráveis.

Por fim, o perfil extremo 3 é discriminado por valores perdidos nas seguintes variáveis: sexo; idade; cor; fez treinamento; jornada de trabalho; tem outros trabalhos; cuida de criança; faz compra em supermercados; leva

TABELA 2

Descrição dos perfis extremos dos trabalhadores de saúde entrevistados conforme discriminação do lambda Belo Horizonte - 2009

\begin{tabular}{llccc}
\hline Variáveis & Categorias & $\mathbf{1}$ & $\mathbf{2}$ & $\mathbf{3}$ \\
\hline Sexo & Homens & 1,5821 & 0,0000 & 0,7550 \\
& Mulheres & 0,7856 & 1,4104 & 1,0368 \\
& Missing & 0,0000 & 0,0000 & 4,8636 \\
Idade & 14 a 19 anos & & & \\
& 20 a 29 anos & 1,8926 & 0,0000 & 0,0000 \\
& 30 a 39 anos & 1,3864 & 0,5296 & 0,5611 \\
& 40 a 49 anos & 1,0992 & 1,0680 & 0,6286 \\
& 50 a 80 anos & 0,9537 & 1,2248 & 0,8186 \\
& Missing & 0,6481 & 1,1166 & 1,8298 \\
& & 0,0000 & 0,0000 & 4,9231 \\
Cor & Branca & & & 0,3083 \\
& Não branca & 1,4387 & 0,6571 & 1,4928 \\
& Missing & 0,6676 & 1,2794 & 1,6551 \\
\hline
\end{tabular}




\begin{tabular}{|c|c|c|c|c|}
\hline Variáveis & Categorias & 1 & 2 & 3 \\
\hline \multirow[t]{3}{*}{ Treinamento } & Não & 1,1707 & 1,0546 & 0,4849 \\
\hline & Sim & 0,9042 & 0,9617 & 1,2987 \\
\hline & Missing & 0,0000 & 0,7784 & 3,8919 \\
\hline \multirow[t]{3}{*}{ Vínculo empregatício } & Não estável & 0,9610 & 0,8948 & 1,2308 \\
\hline & Estável & 1,0760 & 1,0822 & 0,7054 \\
\hline & Missing & 0,0000 & 0,8250 & 3,7214 \\
\hline \multirow{10}{*}{$\begin{array}{l}\text { Jornada semanal de } \\
\text { trabalho (horas) }\end{array}$} & 8 & 0,4000 & 1,0667 & 2,4730 \\
\hline & 10 & 0,0000 & 0,0000 & 0,0000 \\
\hline & 12 & 1,6875 & 0,7000 & 0,0000 \\
\hline & 20 & 1,9315 & 0,0000 & 0,0000 \\
\hline & 24 & 1,8824 & 0,0000 & 0,0000 \\
\hline & 30 & 0,0000 & 2,4719 & 1,4947 \\
\hline & 36 & 1,5941 & 0,5735 & 0,0000 \\
\hline & 40 & 1,1080 & 0,8716 & 0,9325 \\
\hline & 44 & 0,8382 & 1,8059 & 0,4147 \\
\hline & Missing & 0,0000 & 0,0000 & 4,8480 \\
\hline \multirow[t]{9}{*}{ Outros trabalhos } & Prefeitura BH & 1,0969 & 0,3906 & 1,5281 \\
\hline & Outra prefeitura & 1,5768 & 0,6536 & 0,0000 \\
\hline & Estado & 1,1459 & 0,8738 & 0,7754 \\
\hline & Nível federal & 1,5333 & 0,5500 & 0,0583 \\
\hline & Iniciativa privada com carteira assinada & 1,2233 & 0,9767 & 0,4767 \\
\hline & Iniciativa privada sem carteira assinada & 1,6675 & 0,4250 & 0,0000 \\
\hline & Tem outro trabalho por conta própria & 1,6337 & 0,5024 & 0,0000 \\
\hline & Não tem outro trabalho & 0,9789 & 1,2229 & 0,8110 \\
\hline & Missing & 0,0000 & 0,9664 & 3,4422 \\
\hline \multirow{6}{*}{$\begin{array}{l}\text { Jornada } \\
\text { no outro trabalho }\end{array}$} & Menos de 20 horas & 1,4776 & 0,4857 & 0,3959 \\
\hline & 21 a 30 horas & 0,1618 & 2,5039 & 1,1363 \\
\hline & 31 a 40 horas & 1,2977 & 0,8473 & 0,3911 \\
\hline & 41 a 44 horas & 1,3318 & 1,1409 & 0,0000 \\
\hline & Mais de 44 horas & 1,2732 & 0,8301 & 0,4933 \\
\hline & Missing & 0,0000 & 0,8000 & 4,0434 \\
\hline \multirow[t]{3}{*}{ Cuida de criança } & Não & 1,5180 & 0,9384 & 0,0000 \\
\hline & Sim & 1,0688 & 1,7242 & 0,1591 \\
\hline & Missing & 0,0000 & 0,0000 & 4,0123 \\
\hline \multirow{3}{*}{$\begin{array}{l}\text { Faz compras no } \\
\text { supermercado }\end{array}$} & Não & 1,4186 & 0,9455 & 0,0000 \\
\hline & Sim & 0,9770 & 1,0614 & 0,9790 \\
\hline & Missing & 0,0000 & 0,0000 & 4,9780 \\
\hline \multirow{3}{*}{$\begin{array}{l}\text { Leva criança } \\
\text { para escola }\end{array}$} & Não & 1,3539 & 1,4537 & 0,0000 \\
\hline & Sim & 1,3834 & 1,1360 & 0,0000 \\
\hline & Missing & 0,0000 & 0,0000 & 3,7594 \\
\hline \multirow{3}{*}{$\begin{array}{l}\text { Faz pequenos } \\
\text { consertos em casa }\end{array}$} & Não & 1,2427 & 1,2484 & 0,0000 \\
\hline & Sim & 1,0546 & 1,0508 & 0,7428 \\
\hline & Missing & 0,0000 & 0,0000 & 5,2728 \\
\hline \multirow{3}{*}{$\begin{array}{l}\text { Cuida de idosos, } \\
\text { crianças e doentes }\end{array}$} & Não & 1,5056 & 1,0686 & 0,0000 \\
\hline & Sim & 0,6729 & 1,6904 & 1,0084 \\
\hline & Missing & 0,0000 & 0,3643 & 3,4123 \\
\hline
\end{tabular}




\begin{tabular}{|c|c|c|c|c|}
\hline Variáveis & Categorias & 1 & 2 & 3 \\
\hline \multirow{3}{*}{$\begin{array}{l}\text { Responsável pelo } \\
\text { domicílio }\end{array}$} & Não & 1,4777 & 0,4395 & 0,5121 \\
\hline & Sim & 0,6184 & 1,7417 & 1,0053 \\
\hline & Missing & 0,0000 & 0,0000 & 4,8639 \\
\hline \multirow{6}{*}{$\begin{array}{l}\text { Dias dedicados } \\
\text { a trabalho } \\
\text { no domicílio }\end{array}$} & Todos os dias da semana & 0,5803 & 1,8831 & 0,8949 \\
\hline & 3 ou mais dias da semana & 1,2267 & 0,8356 & 0,6370 \\
\hline & 1 ou 2 dias da semana & 1,7076 & 0,3263 & 0,0678 \\
\hline & Apenas no final de semana & 1,2890 & 0,5005 & 0,9119 \\
\hline & Não realizou atividade doméstica & 1,8831 & 0,0000 & 0,0000 \\
\hline & Missing & 0,0000 & 0,0000 & 5,0493 \\
\hline \multirow{3}{*}{$\begin{array}{l}\text { Realiza atividades } \\
\text { de lazer }\end{array}$} & Não & 0,0000 & 3,8606 & 0,0000 \\
\hline & Sim & 1,3699 & 0,0000 & 1,3008 \\
\hline & Missing & 0,0000 & 1,2933 & 3,3600 \\
\hline \multirow{3}{*}{$\begin{array}{l}\text { Realiza atividades } \\
\text { culturais }\end{array}$} & Não & 1,1808 & 0,0000 & 1,9447 \\
\hline & Sim & 1,6045 & 0,0000 & 0,5489 \\
\hline & Missing & 0,0000 & 3,7879 & 0,0000 \\
\hline \multirow{3}{*}{$\begin{array}{l}\text { Realiza atividades } \\
\text { sociais }\end{array}$} & Não & 1,2771 & 0,0000 & 1,6444 \\
\hline & Sim & 1,3942 & 0,0000 & 1,2345 \\
\hline & Missing & 0,0000 & 3,8023 & 0,0000 \\
\hline \multirow{3}{*}{$\begin{array}{l}\text { Realiza atividades } \\
\text { físicas }\end{array}$} & Não & 1,1222 & 0,0000 & 2,0812 \\
\hline & Sim & 1,4719 & 0,0000 & 1,0240 \\
\hline & Missing & 0,0000 & 3,7736 & 0,0000 \\
\hline \multirow{4}{*}{$\begin{array}{l}\text { Frequência de } \\
\text { atividades físicas }\end{array}$} & 3 ou mais vezes por semana & 1,7983 & 0,0000 & 0,4047 \\
\hline & 1 ou 2 vezes por semana & 1,4166 & 0,0000 & 1,5461 \\
\hline & Nunca & 0,3582 & 2,2762 & 0,5823 \\
\hline & Missing & 0,0000 & 2,3971 & 1,5935 \\
\hline \multirow{3}{*}{$\begin{array}{l}\text { Incidência de } \\
\text { depressão e insônia }\end{array}$} & Não & 1,2903 & 0,7548 & 0,5213 \\
\hline & $\operatorname{Sim}$ & 0,0000 & 3,6726 & 0,0000 \\
\hline & Missing & 0,0000 & 0,0000 & 5,3214 \\
\hline \multirow[t]{3}{*}{ Distúrbios de sono } & Não & 1,1973 & 0,9487 & 0,4766 \\
\hline & Sim & 0,7352 & 2,0451 & 0,3415 \\
\hline & Missing & 0,0000 & 0,0000 & 5,3613 \\
\hline \multirow[t]{3}{*}{ Falta ao trabalho } & Não & 0,9944 & 0,8295 & 1,2391 \\
\hline & Sim & 1,0494 & 1,2637 & 0,5251 \\
\hline & Missing & 0,0000 & 0,0000 & 4,8944 \\
\hline \multirow{6}{*}{$\begin{array}{l}\text { Faixa de rendimento do } \\
\text { trabalho }\end{array}$} & Entre meio e 1 salário mínimo & 1,9221 & 0,0000 & 0,0000 \\
\hline & Entre 1 e 2 salários mínimos & 0,4949 & 1,7816 & 1,2686 \\
\hline & Entre 2 e 5 salários mínimos & 0,0000 & 0,0000 & 0,0000 \\
\hline & Entre 5 e 10 salários mínimos & 0,9300 & 1,4296 & 0,6666 \\
\hline & Mais de 10 salários mínimos & 1,9119 & 0,0000 & 0,0000 \\
\hline & Missing & 0,0000 & 0,0000 & 4,5741 \\
\hline \multirow[t]{3}{*}{ SRQ } & TMC negativo & 1,1769 & 0,6850 & 0,9189 \\
\hline & TMC positivo & 0,7973 & 2,1525 & 0,0000 \\
\hline & Missing & 0,0000 & 0,5613 & 4,4600 \\
\hline \multirow[t]{5}{*}{$\mathrm{JCQ}$} & Alta exigência & 1,1620 & 1,3460 & 0,1485 \\
\hline & Trabalho ativo & 1,8848 & 0,0000 & 0,0000 \\
\hline & Baixa exigência & 1,6741 & 0,0000 & 0,5417 \\
\hline & Trabalho passivo & 0,9172 & 1,2105 & 0,9318 \\
\hline & Missing & 0,0000 & 1,0152 & 3,6071 \\
\hline
\end{tabular}


(continuação)

\begin{tabular}{|c|c|c|c|c|}
\hline Variáveis & Categorias & 1 & 2 & 3 \\
\hline \multirow{3}{*}{$\begin{array}{l}\text { Tomou vacina } \\
\text { contra hepatite } B ?\end{array}$} & Não & 0,8264 & 1,0377 & 1,4038 \\
\hline & Sim & 1,0707 & 0,9826 & 0,8380 \\
\hline & Missing & 0,5194 & 1,1320 & 2,1282 \\
\hline \multirow{4}{*}{$\begin{array}{l}\text { Ocupação } \\
\text { compatível com } \\
\text { escolaridade }\end{array}$} & Compativel & 1,2033 & 0,9400 & 0,5418 \\
\hline & Sobrequalificados & 0,4515 & 1,5306 & 1,7687 \\
\hline & Subqualificados & 0,6427 & 1,2463 & 1,6427 \\
\hline & Missing & 0,0000 & 0,0000 & 4,9783 \\
\hline \multirow{3}{*}{$\begin{array}{l}\text { Sobrecarga de } \\
\text { trabalho no domicílio }\end{array}$} & Baixa sobrecarga & 1,6600 & 0,4883 & 0,0000 \\
\hline & Alta sobrecarga & 0,5535 & 2,0484 & 0,6472 \\
\hline & Missing & 0,4845 & 0,5595 & 3,0133 \\
\hline
\end{tabular}

Fonte: Elaboração dos autores a partir dos inquéritos da Pesquisa Condições de Trabalho, Condições de Emprego e Saúde dos Trabalhadores da Saúde, financiada pela Fapemig.

filhos à escola; realiza pequenos consertos; cuida de idosos e doentes; responsabilidade pelo domicílio; dias de trabalho no domicílio; pratica atividade de lazer; faz atividades físicas; distúrbios de sono; falta no trabalho; rendimento; relato compatível com TMC; aspectos psicossociais do trabalho; vacina contra hepatite $\mathrm{B}$; compatibilidade entre escolaridade e ocupação; sobrecarga em atividades domésticas.

Além de a saída de valores perdidos discriminar para todas essas variáveis, ressaltaram-se: idade superior a 50 anos; cor não branca; jornada de 8 e 30 horas semanais; outros trabalhos na própria Prefeitura; prática de atividades de lazer e atividade física uma ou duas vezes na semana; não falta ao trabalho; rendimento de 1 a 2 salários mínimos; ausência de vacina contra hepatite B; sobre ou subqualificado em seu cargo. Entre as variáveis discriminadas sem que os valores perdidos fossem relevantes, encontram-se as seguintes respostas: vínculo não estável; a não prática de atividades culturais; prática e não prática de atividades sociais e físicas. O perfil extremo 3 seria constituído por trabalhadores não vulneráveis, mas que não foram vacinados contra hepatite $B$ e com formação incompatível com o cargo, concentrando indivíduos mais bem inseridos do que os do perfil 2, mais protegidos no tocante à situação de saúde. Talvez esteja refletindo a presença de um grupo de funcionários menos implicados nas atividades de lida direta com o usuário dos estabelecimentos públicos de saúde, situação que explicaria a informação sobre ausência de cobertura vacinal contra hepatite $B$. A existência de cargos comissionados e de confiança política também pode ser evocada para explicar a discrepância entre cargo e escolaridade.

Para transformar esses três perfis extremos em dez perfis puros e mistos, ordenamos os extremos da pior para a melhor situação. Desse modo, considerando-se os indícios de saúde global - fadiga frequente, distúrbios de sono, insônia, depressão e transtornos mentais comuns -, ausência de lazer e características sociodemográficas (renda, sexo e cor), o perfil extremo 2 foi ordenado como o pior, seguido pelo $3 \mathrm{e}$, como melhor, o 1.

\section{Perfis puros e mistos}

Entre os dez perfis gerados, o perfil puro 3 é o que absorve maior número de trabalhadores $(39,13 \%)$, seguido pelo puro $2(14,94 \%)$ e pelo misto que combina 3 e 1 $(11,18 \%)$, de acordo com a Tabela 3.

Tem-se, assim, a descrição desses perfis de acordo com as variáveis mais relevantes dessa análise: estabilidade do vínculo; realização de atividades de lazer; relato compatível com TMC; demandas psicossociais das tarefas; compatibilidade entre escolaridade e ocupação; e sobrecarga nas tarefas domésticas.

De acordo com o Gráfico 1, os perfis de maior proporção de não estáveis foram o misto 1 e 3 e o misto 3 e 1 . Entre os de maior 
TABELA 3

Distribuição dos trabalhadores de saúde entrevistados, segundo perfis Belo Horizonte - 2009

\begin{tabular}{lcc}
\hline Perfis & N. abs. & $\%$ \\
\hline Misto & 119 & 6,59 \\
Puro 1 & 109 & 6,03 \\
Misto 1 e 2 & 48 & 2,66 \\
Misto 1 e 3 & 81 & 4,48 \\
Misto 2 e 1 & 72 & 3,98 \\
Puro 2 & 270 & 14,94 \\
Misto 2 e 3 & 88 & 4,87 \\
Misto 3 e 1 & 202 & 11,18 \\
Misto 3 e 2 & 111 & 6,14 \\
Puro 3 & 707 & 39,13 \\
Total & $\mathbf{1 . 8 0 7}$ & $\mathbf{1 0 0 , 0 0}$ \\
\hline
\end{tabular}

Fonte: Elaboração dos autores a partir dos inquéritos da Pesquisa Condições de Trabalho, Condições de Emprego e Saúde dos Trabalhadores da Saúde, financiada pela Fapemig.

representação da estabilidade no emprego, encontram-se os tipos puro 3 (mais de $60 \%$ ) e misto 2 e 3 (60\%).

Quase a integralidade dos ocupados do perfil puro 3 , assim como no caso dos perfis misto 1 e 3 e misto 3 e 1, realiza atividades de lazer (Gráfico 2). Por sua vez, os perfis puro 2 e misto 2 e 1 são aqueles em que os trabalhadores declararam não praticar atividades de lazer.

O Gráfico 3 ilustra a distribuição dos perfis quanto à frequência de transtorno

GRÁFICO 1

Composição dos perfis, por vínculo empregatício dos trabalhadores de saúde entrevistados Belo Horizonte - 2009

Em \%

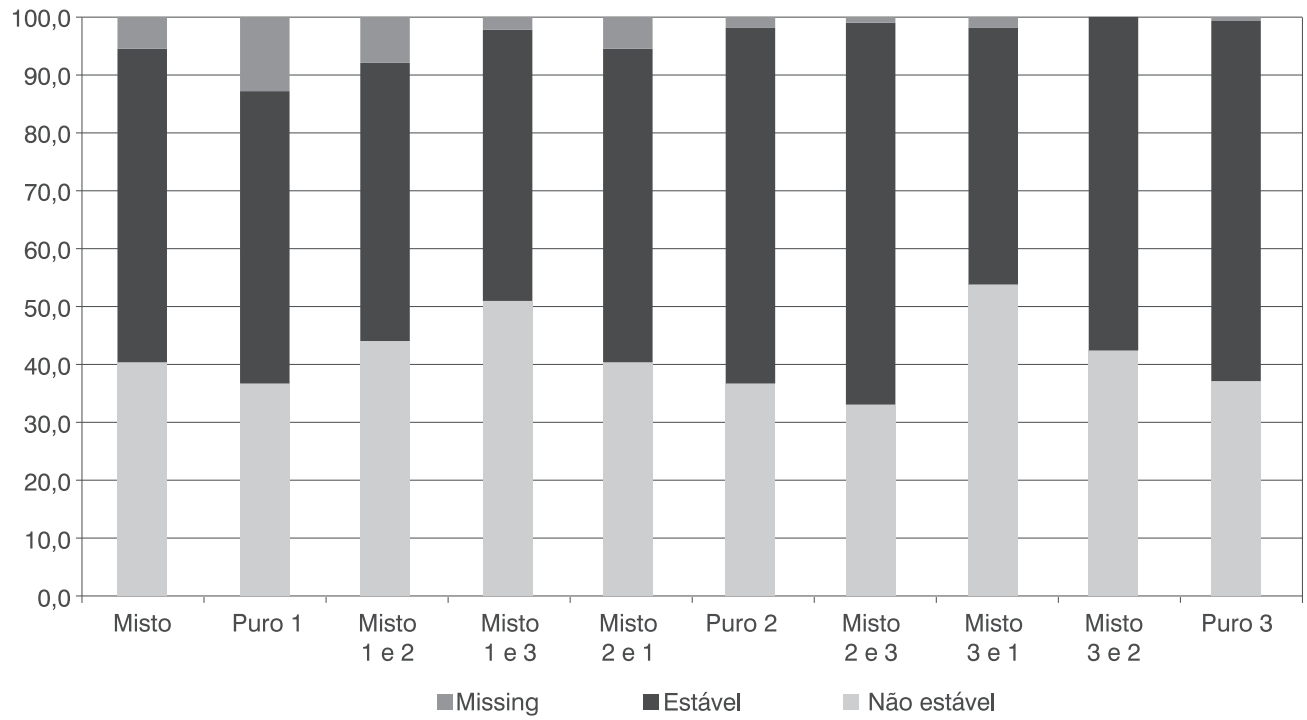

Fonte: Elaboração dos autores a partir dos inquéritos da Pesquisa Condições de Trabalho, Condições de Emprego e Saúde dos Trabalhadores da Saúde, financiada pela Fapemig. 
GRÁFICO 2

Composição dos perfis, por declaração de alocação de tempo para lazer dos trabalhadores de saúde entrevistados

Belo Horizonte - 2009

Em \%

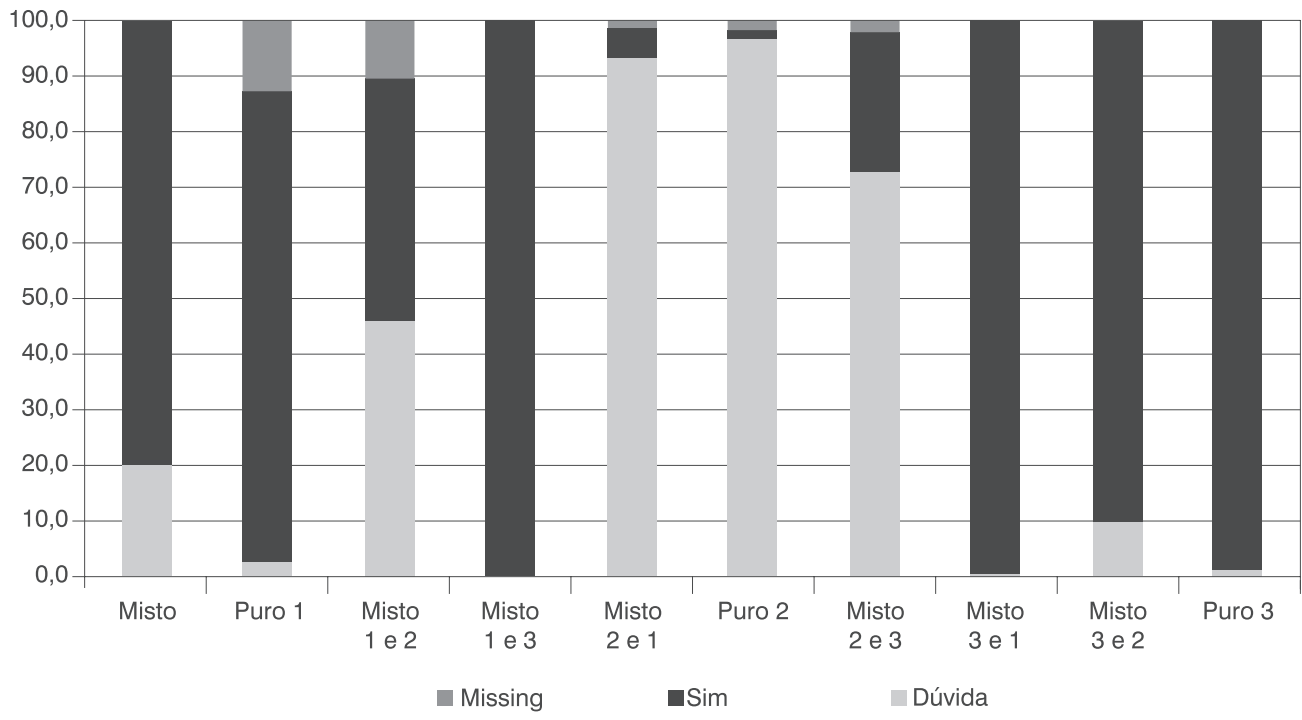

Fonte: Elaboração dos autores a partir dos inquéritos da Pesquisa Condições de Trabalho, Condições de Emprego e Saúde dos Trabalhadores da Saúde, financiada pela Fapemig.

GRÁFICO 3

Composição dos perfis, por transtornos mentais comuns (TMC) dos trabalhadores de saúde entrevistados Belo Horizonte - 2009

\section{Em \%}

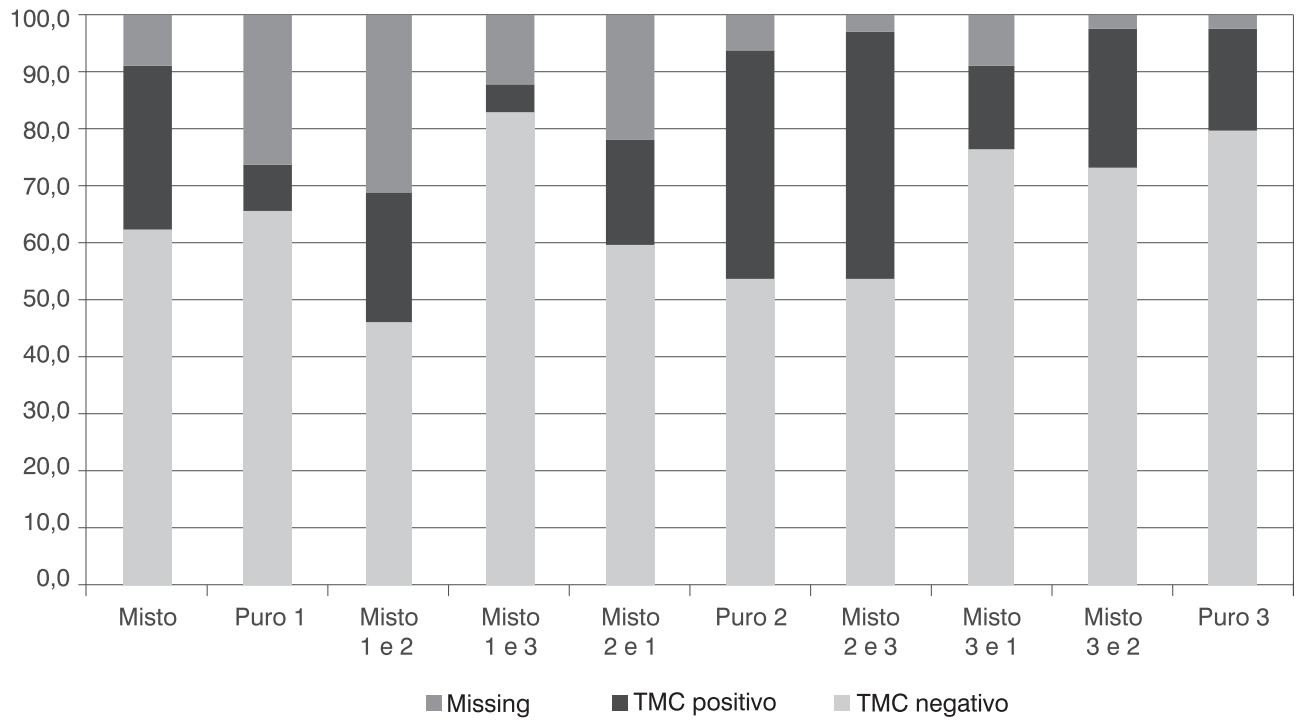

Fonte: Elaboração dos autores a partir dos inquéritos da Pesquisa Condições de Trabalho, Condições de Emprego e Saúde dos Trabalhadores da Saúde, financiada pela Fapemig. 
mental comum. Observa-se que o tipo puro 3 e o misto 1 e 3 apresentam quase $80 \%$ dos trabalhadores com ausência de TMC. A maior prevalência de TMC foi observada no misto 2 e 3 e no puro 2, quase $40 \%$. Mais de $20 \%$ do puro 1 e do misto 1 e 2 são considerados valores perdidos, por não terem respondido as questões da escala (SRQ-20).

A demanda psicossocial do trabalho (traduzida no modelo demanda-controle) está expressa na distribuição dos perfis ilustrados no Gráfico 4. Em todos, prevalece trabalho passivo. No puro 3 e no misto 3 e 1 há aproximadamente $10 \%$ que apontam trabalho ativo. Mais de $20 \%$ apresentam demanda de alta exigência no trabalho nos perfis puro 2 e misto 2 e 3 . Cabe destacar a maioria significativa de trabalho de baixa exigência no puro 3 , comparativamente aos demais grupos.

Os perfis puro 1 e misto 1 e 2 agregaram aproximadamente a metade dos trabalhadores em cargo não compatível com a escolaridade. Nos perfis mistos $1 \mathrm{e}$ 2 e 2 e 1 , cerca de $22 \%$ dos trabalhadores estavam em situação de sobrequalificação. Já no puro 2, misto 1 e 2 e misto 3 e 2, em torno de $10 \%$ dos TS podem ser considerados subqualificados, segundo os critérios adotados (Gráfico 5). A maior proporção de compatibilidade entre escolaridade e ocupação foi observada no puro 3.

Em relação às demais variáveis analisadas, a sobrecarga de trabalho doméstico é a que apresenta maior proporção de valores perdidos em todos os tipos, conforme ilustra o Gráfico 6. Os perfis misto 1 e 2 , puro 2 e misto 3 e 2 apresentam $54 \%$ e $52 \%$, respectivamente, dos TS na condição de alta sobrecarga. Por outro lado, $63 \%$ dos trabalhadores do perfil puro 3 não estão sujeitos à sobrecarga doméstica. De maneira similar, encontram-se $51 \%$ do misto 2 e 3 e $45 \%$ do misto 3 e 1 .

GRÁFICO 4

Composição dos perfis, por demanda-controle dos trabalhadores de saúde entrevistados Belo Horizonte - 2010

$\mathrm{Em} \%$

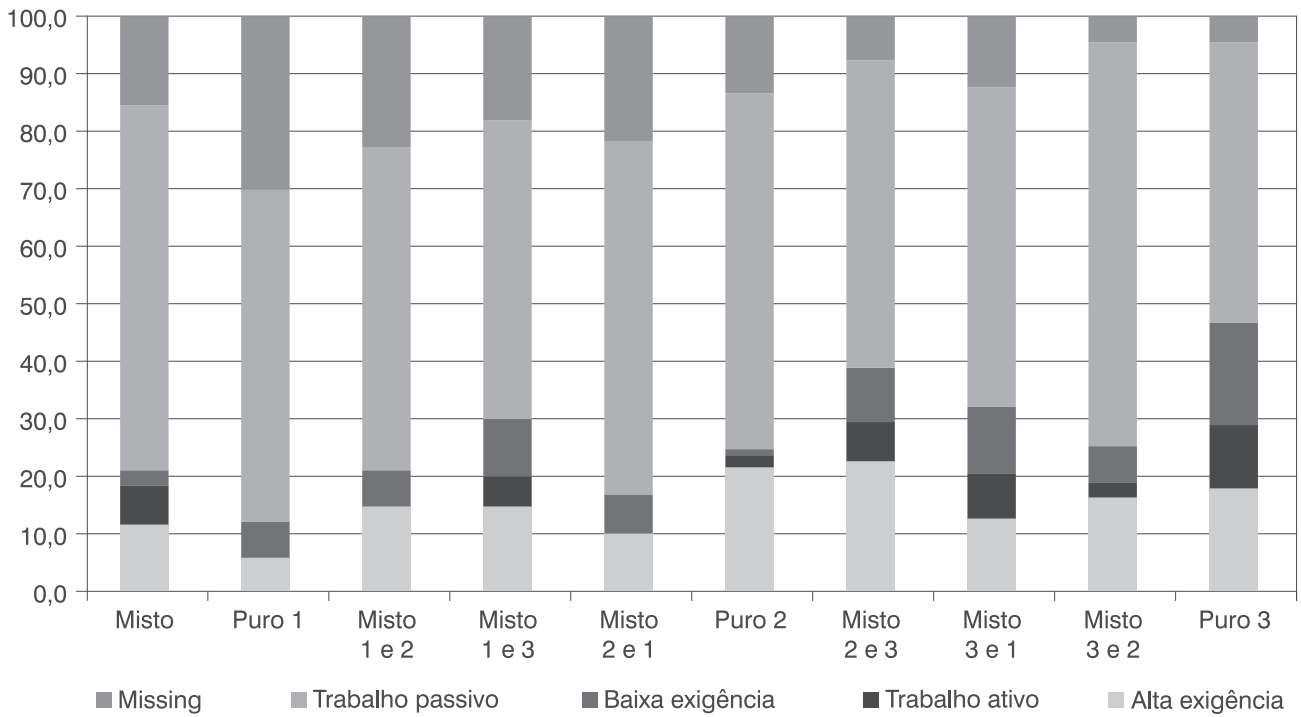

Fonte: Elaboração dos autores a partir dos inquéritos da Pesquisa Condições de Trabalho, Condições de Emprego e Saúde dos Trabalhadores da Saúde, financiada pela Fapemig. 


\section{GRÁFICO 5}

Composição dos perfis, por compatibilidade entre escolaridade e ocupação dos trabalhadores de saúde entrevistados

Belo Horizonte - 2009

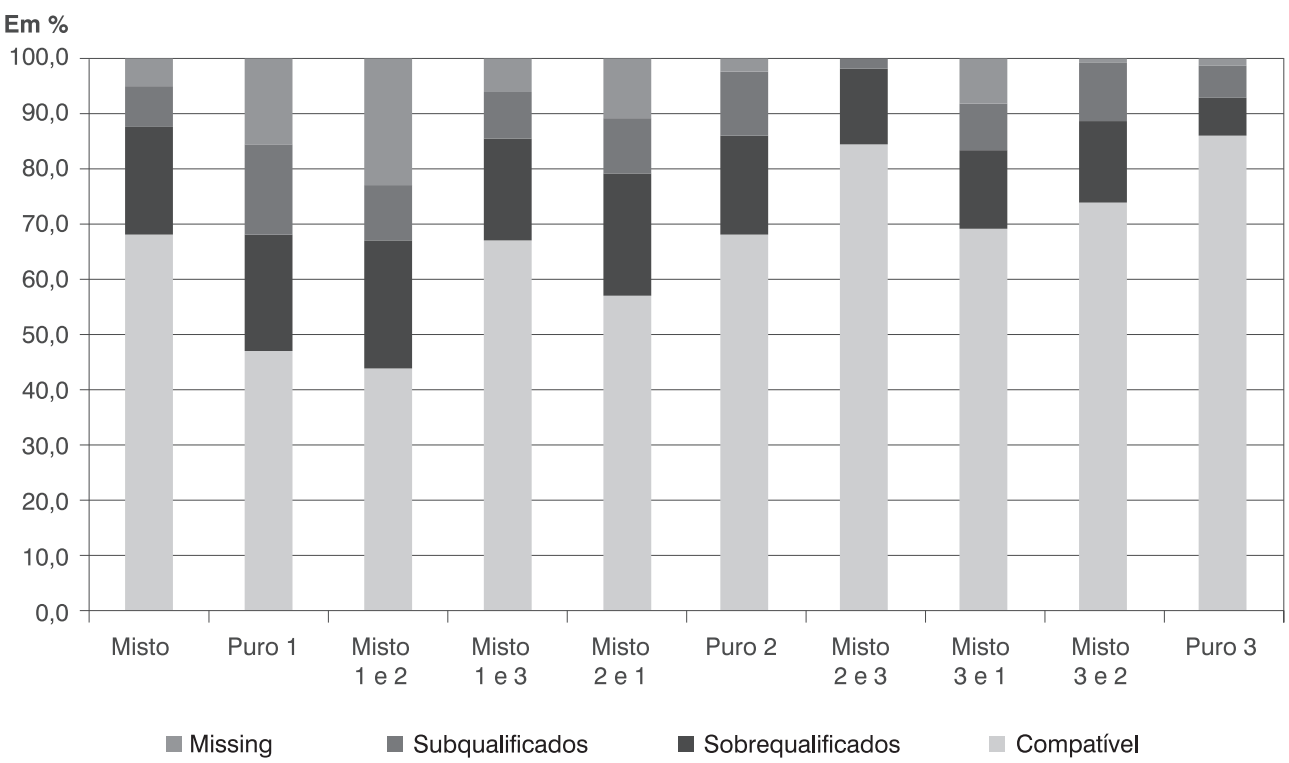

Fonte Elaboração dos autores a partir dos inquéritos da Pesquisa Condições de Trabalho, Condições de Emprego e Saúde dos Trabalhadores da Saúde, financiada pela Fapemig.

GRÁFICO 6

Composição dos perfis, por sobrecarga de trabalho doméstico dos trabalhadores de saúde entrevistados Belo Horizonte - 2009

Em \%

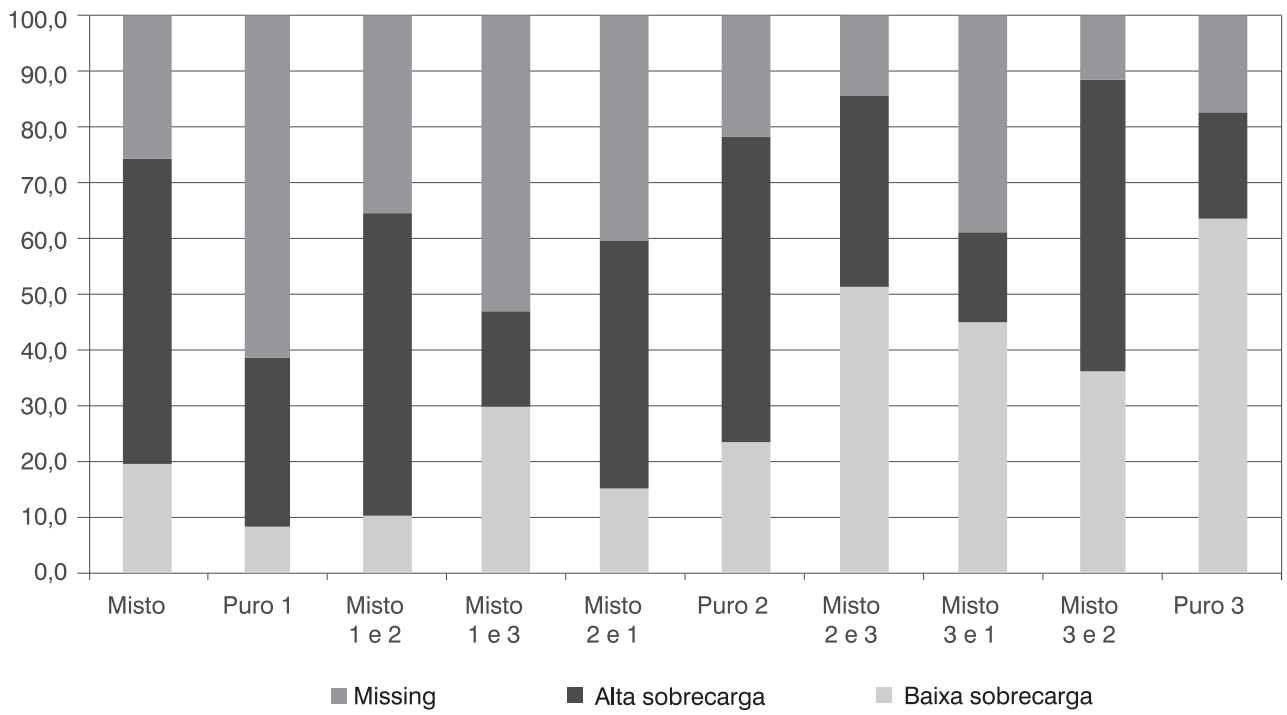

Fonte: Elaboração dos autores a partir dos inquéritos da Pesquisa Condições de Trabalho, Condições de Emprego e Saúde dos Trabalhadores da Saúde, financiada pela Fapemig. 


\section{Discussão}

Com base em variáveis que identificaram características sociodemográficas, hábitos de vida, situações de saúde, características do emprego, aspectos psicossociais do trabalho e trabalho doméstico, o presente estudo utilizou o método GoM para determinar perfis dos trabalhadores de saúde no setor público municipal de Belo Horizonte.

Assim, diante do exposto, foi possível nomear os perfis de acordo com as características identificadas. O tipo puro 3 , de maior frequência na amostra (39\%), é formado pelos trabalhadores em situação de emprego estável, relativamente mais bem remunerados, sem sobrecarga doméstica e que participavam regularmente de atividades de lazer, ocupavam cargos compatíveis com a escolaridade e reportavam situações de saúde favoráveis. Por outro lado, o tipo puro 2 , com cerca de $15 \%$ de participação, abrange trabalhadores com empregos estáveis, relativamente mal remunerados, com alta exigência no trabalho e reportando fragilidades quanto à situação de saúde.

O terceiro perfil mais expressivo foi o misto 3 e 1 (11\%), caracterizado por maior participação masculina, de jovens, com vínculo instável, em situação de trabalho ativo e sem sobrecarga doméstica, saudáveis. Provavelmente, trata-se, em sua maioria, de estagiários. O tipo misto 3 e $2(6,14 \%)$ configurou um perfil de trabalhadores estáveis, relativamente mal remunerados, sem sobrecarga doméstica e com prática de atividades de lazer, subqualificados para seus cargos e mais frágeis quanto à situação de saúde.

O quinto tipo mais representativo foi o puro $1(6,03 \%)$, caracterizado por elevada frequência de valores perdidos, trabalhadores menos jovens, mal remunerados, que alocavam horas para o lazer, saudáveis, mas, sobretudo, o que os distinguia dos demais grupos, além das informações perdidas, foi a fraca compatibilidade entre escolaridade e ocupação.

O perfil misto 2 e 3, com cerca $5 \%$ de ocupados, é composto por trabalhadores jovens, relativamente bem remunerados, com alta exigência no trabalho, baixa sobrecarga doméstica e relatando situações de saúde desfavoráveis. O perfil misto 1 e 3 representa $4,5 \%$ do total, também com frequência expressiva de valores perdidos, embora de vínculo mais instável, com grande proporção de relatos não compatíveis com TMC. Por fim, o tipo 2 e 1 (3,98\% da amostra) está sobrerrepresentado entre os ocupados menos jovens (idade superior a 50 anos) e sobrequalificados. Eles eram relativamente mal remunerados, com significativa parcela recebendo entre 1 e 2 salários mínimos. Apesar de não reportarem práticas de lazer, seus relatos não foram compatíveis com TMC.

\section{Considerações finais}

Como se pode observar, o perfil puro 3, grupo de maior frequência na população estudada, reunia condições menos vulneráveis e situações de saúde mais favoráveis. Vínculos de trabalho estáveis, relativamente bem remunerados, sem sobrecarga doméstica, com participação regular em atividades de lazer e empregos em cargos compatíveis com a escolaridade são fatores que explicariam relatos compatíveis com situações favoráveis de saúde (SIEGRIST; MARMOT, 2004; BRASIL, 2011; PREFEITURA MUNICIPAL DE BELO HORIZONTE, 2007; LOPES; MATOS, 2010; ARAÚJO et al., 2005), comprovadamente observadas nesse grupo.

Registra-se, no entanto, que na amostra estavam presentes dois outros grupos também expressivos, cuja situação de vulnerabilidade ocupacional e de estado de saúde foi menos favorável. O perfil puro $2(15 \%)$ agregou trabalhadores estáveis, porém mal remunerados e trabalhando sob altas exigências psicossociais. Nesse caso, confirmando resultados de estudos anteriores, os relatos indicam fragilidades quanto à situação de saúde.

Relato compatível com TMC distinguiu o perfil misto 2 e 3 dos demais junto às características de executar trabalho do tipo passivo e de não praticar atividades de lazer. É plausível supor que articulações indicadas na literatura entre os referidos fatores (trabalho passivo e ausência 
de lazer) expliquem o perfil, no qual, surpreendentemente, a existência de vínculo estável parece não ter protegido os trabalhadores dos TMC. Não seria imprudente evocar as conhecidas relações entre os efeitos negativos do trabalho passivo e da vida extraocupacional restrita, os quais, no caso, teriam se sobrepostos aos efeitos protetores do vínculo estável. Médicos com estilo de vida saudável, na Holanda, tiveram menor risco para morbidade psiquiátrica em relação àqueles que não adotavam comportamentos saudáveis (GRAHAM et al., 2001). Sabe-se que atividade física vigorosa e regular durante o tempo destinado ao lazer traz efeitos benéficos na redução da tensão, da ansiedade e da depressão, melhorando a autoimagem e o bem-estar (NUNOMURA et al., 2004; MELLO et al., 2005; PITANGA; LESSA, 2005).

Quanto aos aspectos psicossociais, predominaram, no perfil 2 , o trabalho passivo (baixa demanda e baixo controle) e a alta exigência (alta demanda e baixo controle) em TS com pior percepção da saúde (distúrbios de sono e transtornos mentais comuns). Resultados semelhantes foram encontrados numa amostra de trabalhadores de enfermagem em Salvador, Bahia, onde se observou nítido gradiente tipo dose-resposta na associação positiva entre aspectos psicossociais e morbidade psíquica (ARAÚJO et al., 2003a).

Os perfis gerados pela combinação de características de dois ou mais tipos puros - os tipos mistos - facilitam abordar as múltiplas conexões possíveis quando o objeto diz respeito à saúde do trabalhador. Tem-se o perfil misto 3 e 1 - o mais expressivo (11\%) -, no qual predominam homens, jovens, sem relato compatível com sobrecarga doméstica. Tal achado não seria surpreendente, uma vez que a distribuição das atividades doméstica é influenciada pelos determinantes de gênero em benefício dos homens (ARAÚJO et al., 2005; STRAZDINS; BAMMER, 2004).

Resultado inédito, mas plausível, é a declaração unânime de prática de atividades de lazer entre os sujeitos do perfil misto 3 e 1. Entre eles, predominaram maiores salários e trabalho ativo, apesar do vínculo instável, sendo positivos os relatos atinentes à situação de saúde. Pode-se depreender daí que o efeito negativo do vínculo instável sobre a saúde não tenha se manifestado em função de outras situações vivenciadas nesse grupo. Ou seja, a baixa participação no trabalho doméstico, por exemplo, pode ter sido um fator de liberação de tempo para atividades de lazer, exercendo efeito de proteção quanto aos aspectos da saúde, conforme assinala a literatura (PORTELA et al., 2005), compensando os esperados efeitos negativos do vínculo instável (BENACH; MUNTANER, 2007). Além disso, trabalho ativo, outra característica do perfil misto 3 e 1 , também tem sido considerado fator de proteção para morbidades em geral (SIEGRIST; MARMOT, 2004; KARASEK; THEÖRELL, 1990).

Observou-se, contudo, que no perfil misto 2 e 1 articulações entre TMC e práticas de lazer não se manifestaram, pois os sujeitos pertencentes a tal perfil apresentaram relato compatível com ausência de TMC, ao mesmo tempo em que declararam não realizar atividades de lazer. Nesse grupo despontaram os trabalhadores menos jovens, sobrequalificados e menos bem remunerados. Abordagens sobre a trajetória de inserção no emprego seriam benéficas ao evidenciarem dados e análises sobre o percurso ocupacional, esclarecendo sobre possíveis acúmulos já alcançados em ocupações anteriores e construções pessoais facilitadoras para a adoção de estratégias de enfrentamento e de resistência aos riscos das condições vulneráveis.

Algumas vantagens e os limites do presente estudo devem ser citados. O GoM tem sido utilizado por pesquisadores das ciências sociais aplicadas para criar tipologias em que o conjunto analisado é muito heterogêneo. No presente estudo, o método adequou-se ao objetivo porque ajudou na interpretação de perfis mais sintéticos, por meio de número elevado de variáveis. Foi possível nomear e descrever perfis de trabalhadores em saúde a partir da combinação dessas variáveis. Tal procedimento analítico ajudou no reconhecimento das diferenças 
entre os indivíduos e das associações de vulnerabilidades ocupacionais.

A identificação das vulnerabilidades ocupacionais e das situações de saúde em um número razoável de grupos distintos é coerente ao encontrado na literatura sobre o assunto, o que valida os resultados descritos. O tamanho da amostra foi adequado para compor os perfis dos trabalhadores do serviço público de saúde, sendo obtida proporcional e aleatoriamente, com alta taxa de resposta, o que sugere validade interna. Outra vantagem diz respeito à utilização de instrumentos (JCQ, SRQ-20) reconhecidamente validados e amplamente empregados no campo da saúde pública.

A exclusão dos trabalhadores afastados por licença médica, provavelmente, subestimou a real prevalência dos fenômenos de saúde avaliados. É possível também que tenha ocorrido o viés de autorrelato devido ao tipo de coleta de dados que empregou questionários autoadministrados.

Os resultados apresentados convergem para as reflexões acerca da crescente cons-

\section{Referências}

ARAÚJO T. M.; PINHO, P. S.; ALMEIDA, M. M. Prevalência de transtornos mentais comuns em mulheres e sua relação com as características sociodemográficas e o trabalho doméstico. Rev. Bras. Saúde Matern. Infant., n. 5, p. 337-48, 2005.

ARAÚJO, T. M.; AQUINO, E.; MENEZES, G.; SANTOS, C. O.; AGUIAR, L. Aspectos psicossociais do trabalho e distúrbios psíquicos entre trabalhadoras de enfermagem. Rev. Saúde Pública, n. 37, p. 424-33, 2003a.

ARAÚJO, T. M.; GRAÇA, C. C.; ARAÚJO, E. A. Estresse ocupacional e saúde: contribuições do modelo demanda-controle. Cienc. Saúde Coletiva, n. 8, p. 991-1003, 2003b.

ARAÚJO, T. M.; KARASEK, R. Validity and reliability of the job content questionnaire in formal and informal jobs in Brazil. Scand. J. Work Environ. Health, v. 34, supl. 6, p. 52-9, 2008. tatação quanto à vulnerabilidade dos TS às condições de trabalho precárias (MARMOT, 2005; MARMOT et al., 2000). Eles também indicaram a relevância da abordagem da atividade de trabalho, buscando identificar agentes estressores e outros fatores do ambiente relacionados às situações nocivas $e$ de adoecimento (LAHELMA et al., 2009; SIEGRIST; MARMOT, 2004). Algumas características dos indivíduos (idade, sexo, tempo de serviço, etc.), que conformam a população-alvo, não são passíveis de ações externas, no entanto, as políticas podem modificar os fatores localizados em torno do núcleo individual. Exemplificando, os horários de trabalho podem ser modificados, o fluxo de comunicação pode ser melhorado e o apoio social pode ser ampliado. Equilíbrios entre tarefa e sujeito tendem a facilitar a adesão a programas e a motivação pessoal para a mudança de comportamentos relacionados à saúde, como sedentarismo e lazer restrito (MONTEIRO et al., 2003). Todos esses fatores influenciam os efeitos das condições de trabalho sobre a saúde dos TS.

BENACH, J.; MUNTANER, C. Precarious employment and health: developing a research agenda, J. Epidemiol. Community Health, n. 61, p. 276-7, 2007.

BENAVIDES, F. G.; BENACH, J.; DIEZROUX, A. V.; ROMAN, C. How do types of employment relate to health indicators? Findings from the Second European Survey on Working Conditions. J. Epidemiol. Community Health, n. 54, p. 494-501, 2000.

BRASIL. Ministério da Saúde. Portaria 02 de dezembro de 2011. Diretrizes da Política Nacional de Promoção da Saúde do Trabalhador do Sistema Único de Saúde SUS. Brasília, 2011.

BRASIL. Ministério da Saúde. Para subsidiar a discussão sobre a desprecarização do trabalho no SUS. Cadernos RH Saúde, v. 3, n. 1, p. 1-188, 2006.

. Rede Interagencial de Informações para a Saúde - Ripsa. Indicadores de 
recursos. 2009. Disponível em: <http:// tabnet.datasus.gov.br/cgi/deftohtm. exe?idb2010/e01.def>.

BUCHAN J.; FRONTEIRA, I.; DUSSAULT, G. Continuity and change in human resources policies for health: lessons from Brazil. Hum. Resour. Health, v. 9, n. 1, p. 17, 2011.

COELHO, M. C. R. V.; ASSUNÇÃO, A. A.; BELISÁRIO, S. A. Employment and sociodemographic characteristics: a study of increasing precarity in the health districts of Belo Horizonte, Brazil. Hum. Resour. Health, n. 7, p. 1-13, 2009.

CONASEMS - Coordenadoria Nacional de Secretarias Municipais de Saúde. Tema 2 - Gestão do trabalho e educação na saúde. Teses e Plano de Ação. 2006-2007. Disponível em: <www.conasems.org.br>. Acesso em: 22 nov. 2007.

D’AVILA, L. S.; ASSUNÇÃO, A. A.; BELISÁRIO, A. S.; ABREU, D. M. X. Drug dispensing and information giving in Belo Horizonte, Brazil. Inter. J. Health Care Qual. Assur., v. 23, n. 7, p. 643-657, 2010.

GRAHAM, J.; ALBERY, I. P.; RAMIREZ, A. J.; RICHARDS, M. A. How hospital consultants cope with stress a t work: implications for their mental health. Stress Health, n. 17, p. 85-89, 2001.

KARASEK, R. A.; THEÖRELL, T. Healthy work-stress, productivity, and the reconstruction of working life. New York: Basic Books; 1990.

KAUR, S.; SHARMA, R.; TALWAR, R.; VERMA, A.; SINGH, S. A study of job satisfaction and work environment perception among doctors in a Tertiary Hospital in Delhi. Indian J. Med. Scienc., n. 63, p. 4, 2009.

LAHELMA, E.; LAAKSONEN, M.; AITTOMÄKI, A. Occupational class inequalities in health across employment sectors: the contribution of working conditions. Int. Arch. Occup. Environ. Health, n. 82, p. 185-190, 2009.

LOPES, M. I. P.; MATOS, S. G. A construção da mudança do modelo da atenção com ênfase na atenção primária. In: MAGALHÃES JR., H. M. (Org.). Desafios e inovações na gestão do SUS em Belo Horizonte: a experiência de 2003 a 2008. Mazza Edições, 2010, p. 127-147.

MACHADO, M. H.; KOSTER, I. Emprego e trabalho em saúde no Brasil: as políticas de desprecarização do sistema único de saúde. In: ASSUNÇÃO, A. A.; BRITO, J. C. Trabalhar na saúde: experiências cotidianas e desafios para a gestão do trabalho e do emprego. Rio de janeiro: Fiocruz, 2011.

MANTON, K. G.; WOODBURY, M. A.; TOLLEY, H. D. Statistical applications using fuzzy sets. New York: John Wiley \& Sons, 1994.

MARCHAL, B.; KEGELS, G. Health workforce imbalances in times of globalization: brain drain or professional mobility? Int. J. Health Plann. Manage., n. 18, Suppl 1, p. 89-101, 2003.

MARMOT, M. Social determinants of health inequalities. Lancet, n. 365,p.1099-104, 2005.

MAWN B.; SIQUEIRA, E.; KOREN, A.; SLATIN, C.; DEVEREAUX, M. K.; PEARCE, C. Health disparities among health care workers. Qual. Health Res., n. 20, p. 6880, 2010.

MELLO, M. T.; BOSCOLO, R. A.; ESTEVES, A. M.; TUFIK, S. O exercício físico e os aspectos psicobiológicos. Rev. Bras. Med. Esporte, n. 11, p. 203-7, 2005.

MELO, F. L. B. Trajetórias no mercado de trabalho: perfis socioocupacionais de indivíduos e casais da Grande São Paulo. Tese (Doutorado em Demografia) Centro de Desenvolvimento e Planejamento Regional, Universidade Federal de Minas Gerais, 2006.

MONTEIRO, C. A. et al. A descriptive epidemiology of leisure-time physical activity in Brazil, 1996-1997. Rev. Panam. Salud. Publica, n. 14, p. 246-54, 2003.

NUNOMURA, M.; TEIXEIRA, L. A. C.; CARUDSO, M. R. F. Nível de estresse em adultos após 12 meses de prática regular de atividade física. REMEFE, n. 3, p. 12134, 2004. 
OMS - Organización Mundial de la Salud. El Foro Mundial pide acciones inmediatas para resolver la crisis mundial de personal sanitario. Comunicado de Presa, 06/03/2008. Disponível em: <http://www. who.int/mediacentre/news/releases/2008/ pr06/es/print.html>.

PITANGA, F. J. G.; LESSA, I. Prevalência e fatores associados no lazer em adultos. Cad. Saúde Pública, n. 21, p. 870-77, 2005.

PORTELA, L.; ROTENBERG, L.; WAISSMAN, W. Health, sleep and lack of time: relations to domestic and paid work in nurses. Rev. Saúde Pública, n. 39, p. 802-8, 2005.

PREFEITURA MUNICIPAL DE BELO HORIZONTE. Edital 02/2007. Diário Oficial do Município, nov. 2007.

SANTOS, K. O. B.; ARAÚJO, T. M.; OLIVEIRA, N. F. Estrutura fatorial e consistência interna do Self-Reporting Questionnaire (SRQ-20) em população urbana. Cad. Saúde Pública, n. 25, p. 214-222, 2009.

SECRETARIA MUNICIPAL DE SAÚDE DE BELO HORIZONTE. Avanços e desafios na organização da atenção básica à saúde de Belo Horizonte. Belo Horizonte: Editora Brasil Ltda., 2008.

SIEGRIST, J.; MARMOT, M. Health inequalities and the psychosocial environment: two scientific challenges. Soc. Sci. Med., n. 58, p. 1463-1473, 2004.
SMITH, D. R.; LEGGAT, P. A.; ARAKI, S. Emerging occupational hazards among health care workers in the new millennium. Health, n. 45, p. 595-597, 2007.

SOUZA, S. F.; CARVALHO, F. M.; ARAÚJO, T. M.; PORTO, L. A. Fatores psicossociais do trabalho e transtornos mentais comuns em eletricitários. Rev. Saúde Pública, n. 44, p. 710-7, 2010.

STRAZDINS, L.; BAMMER, G. Women, work and musculoskeletal health. Soc. Sci. Med., n. 58, p. 997-1.005, 2004.

TARNOW-MORDI, W. O.; HAU, C.; WARDEN, A.; SHEARER, A. J. Hospital mortality in relation to staff workload: a 4-year study in an adult intensive-care unit. The Lancet, n. 356(9225), p.185-18, 2000.

THIERNEY, D.; ROMITO, P.; MESSING, K. She ate not the bread of idleness: exhaustion is related to domestic and salaried working conditions among 539 Québec hospital workers. Women Health, n. 16, p. 21-42, 1990.

WADA, K.; ARIMATSU, M.; YOSHIKAWA, T.; ODA, S.; TANIGUCHI, H.; HIGASHI, H.; AIZAWA, Y.; KAWASHIMA, M. Physician job satisfaction and working conditions in Japan. J. Occup. Health, n. 51, p. 261-266, 2009.

WALLACE, J. E.; LEMAIRE, J. B.; GHALI, W. A. Physician wellness: a valores perdidos quality indicator. Lancet, n. 374 , p. 171421, 2009.

\section{Resumen}

Vulnerabilidades ocupacionales y percepción de la salud en trabajadores del SUS

Este artículo desarrolla una tipología de precariedad en los vínculos laborales, teniendo en cuenta otras dimensiones, además de aquellas consideradas tradicionales, como el tipo de vínculo, jornada y rendimiento de trabajo. Otros aspectos del lugar de trabajo, y de la distribución del tiempo en actividades y tareas fuera del ambiente laboral, afectan a la inserción de los individuos en el mercado de trabajo. Así pues, a partir de la flexibilidad del método que se menciona a continuación, y de la relativamente gran disponibilidad de información sobre el individuo y su desempeño socioeconómico, la presente investigación recurrió a la aplicación del método Grade of Membership (GoM), contando con los datos de 1.808 trabajadores de la red municipal de salud de Belo Horizonte que participaron en un estudio epidemiológico en 2009. Se consideraron susceptibles de elección todos los profesionales vinculados al servicio público municipal de salud, independientemente del vínculo laboral (permanente, temporal, prácticas). El estudio fue aprobado por el Comité de Ética en Investigación de la Universidad 
Federal de Minas Gerais (dictamen no 542/07). Los resultados presentados convergen hacia reflexiones acerca de la creciente constatación de la vulnerabilidad de los trabajadores de salud en función de las condiciones de trabajo precarias, además de indicar la relevancia del enfoque de la actividad de trabajo, en el sentido de identificar agentes estresores y otros factores del ambiente relacionados con situaciones nocivas y de enfermamiento. Algunas características de los individuos (edad, sexo, tiempo de servicio, etc.) que conforman la población objetivo no son pasibles de acciones externas, no obstante, las políticas pueden modificar los factores localizados en torno al núcleo individual.

Palabras-clave: Mercado de trabajo. Salud. Vulnerabilidad. Trabajadores del SUS. Tipología GoM.

\section{Abstract \\ Occupational vulnerability and health perception of employees of the Brazilian Unified Health System (SUS)}

This investigation describes a typology for instability of work contracts, focusing beyond parameters traditional used, such as type of contract, working hours and work productivity. Others aspects of the working place and time allocation for activities and tasks outside the working environment affect the insertion of individuals in the work market. Thus, considering the flexibility of the method and the extensive availability of data on subjects and their socioeconomical development, we applied the Grade of Membership (GoM) Method to data collected from 1,808 workers of the municipal health network of Belo Horizonte. Subjects participated in an epidemiological survey performed in 2009. All professionals working at public municipal health services were considered eligible for the study, regardless of their working contract (stable, temporary, trainee). The study was approved by the Research Ethics Committee of Universidade Federal de Minas Gerais (approval n. 542/07). Results showed the increasing vulnerability of workers belonging to the health sector due to sub-standard working conditions. The results also indicated the importance of studying work activities to identify stress agents and other environmental factors associated with harmful situations and with illness. Some of the individual characteristics of the target population (age, gender, years of work, etc.) are not susceptible to external actions, although policies can change factors involving individuals.

Keywords: Work market. Health. Vulnerability. SUS workers. GoM Typology.

Recebido para publicação em 03/10/2011 Aceito para publicação em 01/01/2012 